\section{Getting ready for}

\section{Framework 7}

Sean McCarthy ( sean.mccarthy@hyperion.ie)

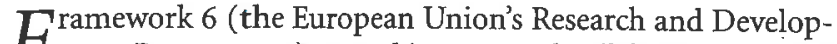
$H$ ment Programme) started in 2003 and will finish at the end of 2006. Framework 7 is expected to begin in 2007. The formal political process that will be used to prepare Framework 7 will take approximately two years to complete. In addition to the formal process, many studies, reviews, evaluations and assessments will be undertaken to decide on the structure, priorities and content of the programme. This article provides an overview of the process that will be used to prepare Framework 7. It will also describe the new directions of the programme. The websites mentioned in this paper can be found on www.hyperion.ie/fp7websites.htm

\section{How Framework 7 will be prepared.}

Figure 1 shows the different players involved in the preparation of Framework 7. Between 2004 and 2006, the budget, structure and rules for Framework 7 will be decided by the European Commission and the Political Institutions (the European Parliament and the Council of Ministers). When this process is complete, the European Commission will 'implement' the programme between 2007 and 2011.

The following diagrams will show the individual steps involved in the preparation of Framework 7 and will then identify how researchers can contribute to the debate or monitor the progress of the debate.

\section{Step 1.The European Commission will 'Propose' FP7}

In early 2005, the European Commission will formally publish a 'Proposal for the Framework 7 Programme' (Figure 2). This is one of the Commission main powers - no debate on any new programme or policy can start until they are ready.

\section{Step 2. The European Parliament is 'Consulted'}

The 'Proposal' is sent to the European Parliament for consultation (Figure 3). Here the Parliament can totally 'reject' the proposal or it can recommend 'amendments'. When the proposal for Framework 6 was first submitted - the European Parliament gave it over 600 amendments. The 'Proposal for Framework 7' will be returned to the European Commission and an 'Amended Proposal for Framework 7' will be submitted some months later. Again there will be more 'amendments' by the European Parliament. This process will continue throughout 2005 and early 2006.

\section{Step 3. The Council'Adopts' the Proposal for Framework 7}

The process described in Step 2 will continue until the Council of Ministers are happy with the structure of the Framework 7 programme. This is a critical part of the process. The debate will end when the 'Council Adopts the Framework 7 Proposal'. This is the main power of the Council of Ministers (Figure 4). This is expected to happen in May 2006.

\section{Step 4. The Commission 'Implements' Framework 7}

At this point, the 'Proposal for Framework 7 ' will be returned to the European Commission (Figure 5). They will then use this document to design the detailed workprogrammes. Following this, 'Calls for Proposals' will be published. The preparation of the workprogrammes should be completed in late 2006 and the first 'Calls for Proposals' should be published in early 2007.

\section{Discussions on Framework 7 (December 2004)}

The Budget: Already a figure of $€ 30$ billion has been suggested (compared to a budget of $€ 17.5$ billion for Framework 6). This will be debated and decided on in early 2005. The proposal to date is that the programme should be divided into five main areas:

- Maintain Policy Driven Research (like Framework 6)

- Basic Research to be included with extra funding.

- 'Technology Platforms'

- Coordination of National Research Programmes (ERA-Net type activities)

- Development of Human Resources and Infrastructures

\section{Basic Research in FP7}

This is the most important new issue to date. In January 2004 the European Commission published a Communication entitled: Europe and Basic Research COM (2004) 9 of 14.1.2004 http://europa.eu.int/comm/research/press/2004/pdf/acte_en_version_final_15janv_04.pdf

In February 2004, an EU symposium on Basic Research was held in Dublin. The conclusions of this symposium recommended the inclusion of basic research in Framework 7. The conclusions of the symposium can be found on www.eu2004.ie/templates/news.asp?sNavlocator $=668$ list_id $=271$ This is the first time that a specific programme on Basic Research will be included in the Framework programme. The evaluation criteria will be 'Excellent Science' only. All of the other usual criteria (partners, deliverables, industrial involvement etc.) will not be used in the evaluation process.

\section{Technology Platforms}

This is the next new item on the agenda for Framework 7. The Commission has already launched 22 'Technology Platforms'. Details of these can be found on a special website on 'Technology Platforms' on www.cordis.lu/technology-platforms/. Examples of the platforms that have been launched are:

\section{- Hydrogen and Fuel Cells Technology Platform (launched in} 2004)

- Steel Technology Platform

- Water Supply and Sanitation Technology Platform (to be launched 2005)

- Mobile Communications and Technology Platform (part of European Growth Initiative)

\section{How to Monitor and Participate in the debate on Framework 7}

The following are the sources of information to follow the developments of FP7. All of these websites can be found on www.hyperion.ie/fp7websites.htm

\section{How to Stay up to date with FP7}

- FP7 on Cordis: Cordis has set up a website www.cordis.lu/fp7/ 
- FP7 on Europa (EU official website) http://europa.eu.int/ comm/research/future/index_en.html

- Cordis News www.cordis.lu/news/Any topics on Basic research, technology platforms, coordination of national programmes etc. will be published in Cordis News..

- EURAB: The European Research Advisory Board is a high level advisory group, consisting of 45 experts. They provide the commission with advice on the progress of FP6 and on future directions (FP7). Their reports can be found on http://europa.eu.int/comm/research/eurab/inded_en.html

\section{How researchers can contribute to the debate on FP7}

- National inputs to FP7: Every EU Member State will make a for mal submission to the debate on FP7. These submissions will be based on information supplied by researchers. This is the best opportunity that scientists have to ensure that their research topic is not omitted from FP7. Examples can be seen on UK www.ost.gov.uk/ostinternational/fp7 - France http://eurosfaire.prd.fr/7pc/forum - Ireland www.forfas.ie/ events/consultation.html

- EU Conferences on FP7: Researchers can contribute to FP7 through a number of special conferences that are organised as part of the EU Presidency. During the first six months of 2004 the presidency was held by Ireland www.eu2004.ie. During the last six months of 2004 the presidency was held by The Netherlands www.eu2004.nl.

- Other Conferences contributing to FP7: A range of conferences being organised to prepare submissions to FP7. These can be found on www.cordis.lu/news/.

- Submissions by EU R\&D Associations: Most European Research Associations will make a formal submission to the debate on FP7. Examples of organisations that will make formal submissions (by sector) can be found on www.hyperion.ie/euassociations.htm - Preparatory Actions (FP6): During FP6 the European Commission funded a number of projects to identify future topics for research. These were called Specific Support Actions and can be found on http://www.cordis.lu/fp6/projects.htm.

- EAGS: The European Commission has set up External Advisory Groups to act as external advisors for FP6. These experts are also used in the preparation of new programmes. They can be found on www.cordis.lu/fp6/eags.htm

\section{Conclusion:}

The preparation of Framework 7 is at full speed. For Research Managers, it is essential to be able to follow, and more importantly, to be part of the preparation of Framework 7. By following the development of Framework 7, research managers will be able to provide better advice to researchers on the background to the programme and on new evaluation criteria. The new directions that will be proposed for Framework 7 will be tested during the Framework 6 programme. This is an important consideration, especially for research proposals that will be submitted towards the end of the Framework 6 programme (2005 and 2006). For the New Member States, the development of Framework 7 is a good opportunity to monitor and learn the decision making process of the European Union.

\section{About the author}

Dr. Sean McCarthy (sean.mccarthy@hyperion.ie) is Managing Director of Hyperion Ltd. Hyperion specialises in the development of training course for research managers. Full details of their training courses can be found on www.hyperion.ie. Hyperion's clients can be seen on www.hyperion.ie/clients.htm
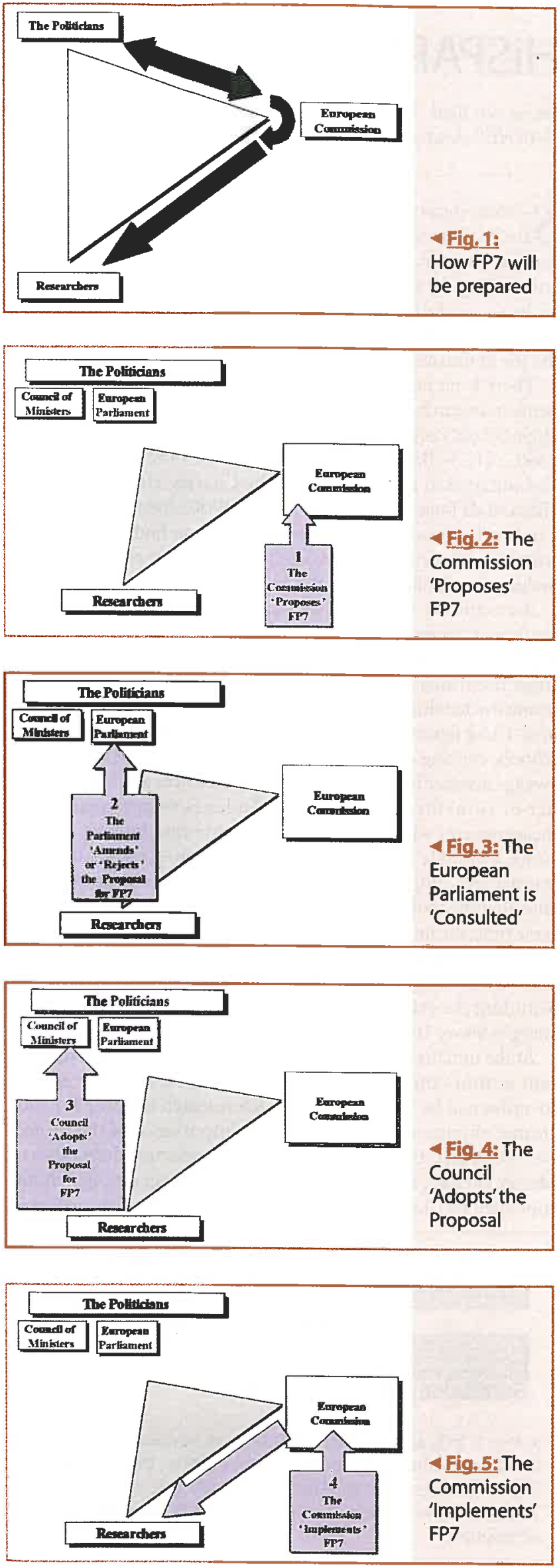